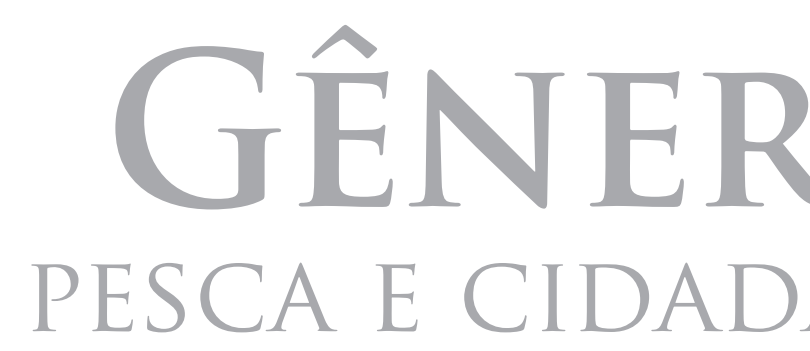




\section{GÊNERO, PESCA E CIDADANIA}

MARIA DO ROSÁRIO F. ANDRADE LEITÃO

UNIVERSIDADE FEDERAL DE SANTA CATARINA, BRASIL 


\title{
GÊNERO, PESCA E CIDADANIA
}

\section{Resumo}

O artigo aborda questões relacionadas à divisão sexual do trabalho a partir de pescadoras artesanais em cinco estados brasileiros, envolvendo três regiões do país: Norte (Pará), Sul (Santa Catarina) e Nordeste (Pernambuco, Ceará e Paraíba). O projeto contou com o apoio de quatro Universidades: UFRPE, UFSC, UFPA e UFBA. Os dados foram coletados nos anos de 2010 e 2011, utilizando-se instrumentais da metodologia participativa. Os relatos das mulheres evidenciaram questões cruciais relacionadas ao seu cotidiano, destacando-se: discriminação ou invisibilidade da mulher na cadeia produtiva da pesca, desconhecimento de muitas pescadoras sobre o acesso aos direitos sociais no regime de economia familiar na pesca artesanal, dificuldades de acesso aos espaços de poder dentro das Colônias e Associações de pescadores/as, riscos e dificuldades de acesso aos Equipamentos de Proteção Individual (EPI's), presença de atravessadores e a necessidade de um comércio justo.

Palavras-chave: Gênero, pesca, cidadania.

\section{GENDER, FISHING, AND CITIZENSHIP}

\begin{abstract}
This paper discusses the sexual division of labor of artisanal fishers in five Brazilian states, involving three regions of the country: North (Pará), South (Santa Catarina), and Northeast (Pernambuco, Ceará and Paraiba). The project was supported by four universities: UFRPE, UFSC, UFPA and UFBA. Data was collected in 2010 and 2011, employing participatory methodology. The women's stories showed critical issues related to their daily lives, such as: discrimination or invisibility of women in the fisheries' production chain, lack of knowledge of many fisherwomen on access to social rights in the family economy regime of artisanal fisheries, difficulties of access to positions of power within the Colonies and Associations of fishermen/women, risks and difficulties of access to the Personal Protective Equipment (PPE), presence of middlemen and the need for fair trade.
\end{abstract}

Keywords: Gender, fishing, citizenship. 


\section{GÉNERO, PESCA Y CIUDADANÍA}

\section{Resumen}

El ensayo trata de cuestiones relacionadas a la división sexual del trabajo de las pescadoras artesanales en cinco provincias brasileñas, involucra tres regiones del país: Norte (Pará), Sur (Santa Catarina) y Noreste (Pernambuco, Ceará y Paraíba). El proyecto contó con el apoyo de cuatro Universidades: UFRPE, UFSC, UFPA y UFBA. Los datos fueron colectados en los años 2010 y 2011 con instrumentales de metodología participativa. Los relatos de estas mujeres llaman la atención sobre importantes cuestiones relacionadas al cotidiano de ellas, se destacan: discriminación o invisibilidad de la mujer en la cadena productiva de la pesca; desconocimiento por parte de muchas pescadoras acerca de los derechos sociales en la economía familiar de la pesca artesanal; dificultades de acceso a los espacios de poder en las Colonias y Asociaciones de pescadores; los riscos y dificultades de acceso a los equipamientos individuales de seguridad; la necesidad de comercio justo y directo al consumidor.

Palabras clave: Género, pesca y ciudadanía.

Endereço para correspondência: Departamento de Ciências Sociais. Universidade Federal Rural de Pernambuco - UFRPE, Rua Dom Manoel de Medeiros, s/n, Dois Irmãos - CEP 52171-900 - Recife/PE. E-mail: rosario@ dlch.ufrpe.br 


\section{INTRODUÇÃO}

"A cidadania é fundamental porque ela está ligada a questão de gênero, classe, raça e desenvolvimento sustentável"(Enilde Lima Oliveira, Presidente da Colônia Z-9/São José da Coroa Grande/PE, em 10/12/2010).

Ao iniciarmos a pesquisa "Ações para Consolidar a Transversalidade de Gênero nas Políticas Públicas para a Pesca e Aquicultura", convênio 078/2009 do Ministério da Pesca e Aquicultura, fomos surpreendidos com as narrações sobre o cotidiano das pescadoras no que se refere ao trabalho, à saúde e à alimentação das pescadoras artesanais de cinco estados brasileiros, envolvendo três regiões do país: no Norte, o Pará; no Sul, Santa Catarina e no Nordeste Pernambuco, Ceará e Paraíba.

"A nossa profissão nos dá alegria do nosso trabalho, mas em compensação a gente tem muita dificuldade, porque a gente, não tem quem compre direto, a gente tem um frigorífero aqui em Icapuí, que é do Sr. (....), ele compra, mas não tem um preço justo, e a gente trabalha, trabalha demais para conseguir pouco dinheiro nesta nossa profissão.” (Linduína, 58 anos, Ceará)

"No momento só coleto marisco (pedra, sururu, ostra) e caranguejo, vendo aos atravessadores $1 \mathrm{~kg}$ por $\mathrm{R} \$ 8,00$ e aos veranistas por $R \$ 10,00$. Para pegar os mariscos ou vai andando ou de barco, é perigoso quando tem vento muito forte, o barco pode afundar e corro risco de morte porque não sei nadar." (Josineide, 36 anos, Paraíba)

“Tem Colônia que não aceita a mulher, a mulher continua discriminada e tem mulheres que não sabem os direitos e os deveres que ela tem como pescadora ou trabalhadora em regime de economia familiar, porque nós temos direito a tirar carteira." (Joana Mousinho, 54 anos, Pernanmbuco)

"Sou viúva, pesco no mar, conserto redes e barcos, trabalho como um homem dou até nó de guia, ${ }^{1}$ fui presidente de colônia por seis meses.” (Nair, 60 anos, Santa Catarina)

"Eu me dediquei completamente à pesca porque eu queria ajudar meu pai. Depois pescava com meu companheiro e, depois ao ser abandonada, pescava sozinha. Eu mesmo ia catar os mariscos, debulhava o marisco, cozinhava e ia vender no supermercado, no hotel, e assim eu sobrevivo da pesca." (Lourdes/Pará)

No processo de escolha das localidades conhecíamos dados quantitativos relacionados aos números indicativos $\mathrm{da}$ distribuição nacional de pescado por estado, que em 2008 apontam Santa Catarina como o maior produtor, seguido pelo Pará. No que diz respeito aos dados do Registro Geral da Pesca (RGP) até 31/12/2009, a região Nordeste apresenta o maior número de pescadores do país, ou seja, 46,3\% do total, seguido pela região Norte com $31,9 \%$; juntas essas regiões respondem por $78,3 \%$ do universo de pescadores profissionais do Brasil.

A definição do recorte espacial da pesquisa também foi ancorada nos dados do Boletim Estatístico da Pesca e Aquicultura no Brasil 2008-2009, cujos dados indicam que existem no Pará 
167.494 pescadores, sendo 102.558 homens $(61,2 \%)$ e 64.936 mulheres $(38,8 \%)$; em Pernambuco 14.452 pescadores, 8.713 homens $(60,3 \%)$ e 5.739 mulheres (39,7\%); no Ceará 30.184 pescadores, dos quais 24.161 homens $(80 \%)$ e 6.023 mulheres (20\%); na Paraíba 19.543 pescadores, 14.077 homens $(72 \%)$ e 5.466 mulheres (28\%); em Santa Catarina 38.934 pescadores, 25.245 homens $(64,8 \%)$ e 13.689 mulheres $(35,2 \%)$.

Os dados quantitativos foram fundamentais na definição do recorte metodológico deste diagnóstico, pois a partir deles nos debruçamos sobre esta realidade para assim alcançar, por meio de entrevistas, fotografias e depoimentos, informações que ultrapassam os dados numéricos, com a intenção de dar voz e visibilidade a estas mulheres pescadoras oriundas de Baía do Sol, Mosqueiro, Curuçá, Icapuí, Fortim, Acaú, Itacuruba, Santa Maria da Boa Vista, Jatobá, Ibimirim, Itapissuma, Governador Celso Ramos, Brasília Teimosa, Rio Formoso, São José da Coroa Grande e Igarassú.

Estes relatos impactantes são muito contundentes e apresentam questões semelhantes, apesar das especificidades das diferentes regiões. Nestas cinco citações são abordadas questões cruciais relacionadas ao cotidiano destas mulheres, onde se destacam: discriminação ou invisibilidade da mulher na cadeia produtiva da pesca, o desconhecimento de muitas pescadoras sobre o acesso aos seus direitos sociais na pesca artesanal, a dificuldade de acesso aos espaços de poder dentro das Colônias e Associações de pescadores/as; os riscos e dificuldades de acesso aos Equipamentos de Proteção Individual (EPI's); a presença do atravessador e a necessidade de um comércio justo.

Neste artigo se busca visibilizar o discurso por elas construído sobre seu cotidiano na pesca artesanal suas lutas e deslocamentos no âmbito econômico, cultural, social e político. O conjunto das respostas possibilita debater os temas trabalho, saúde e alimentação, na pesquisa que realizou oficinas em cinco estados do Brasil: Pernambuco, Santa Catarina, Pará, Ceará e Paraíba durante os anos de 2010 e 2011. Aqui, o recorte privilegiou a divisão sexual do trabalho na pesca artesanal.

\section{A TRAJETÓRIA DA PESQUISA}

As atividades foram iniciadas com o debate e interesse por aprofundar as questões metodológicas em estudos de gênero, considerando que as diferenças culturais entre sujeitos na pesquisa apresentavam entraves à comunicação e consequentemente lacunas ou distorções na coleta de dados. Neste contexto, o diálogo mediado, entre diferentes atores sociais, pode abrir espaço para troca de saberes, a partir de instrumentos de metodologia participativa.

Para isso, faz-se importante ressaltar qual o conceito de mediação/moderação estabelecido nesta prática:

"Moderação compreende a 'condução de processo de discussão’ cujo objetivo é promover a participação ativa de todos os integrantes do grupo na construção final do produto. Através de uma discussão 
objetiva e equilibrada (regulada e dentro de 'limites justos') procurase criar um ambiente de confiança facilitando a comunicação entre os integrantes do grupo, orientando suas reflexões em direção aos objetivos deste para que se chegue aos resultados esperados. É importante que fomente a criatividade, colaborando para um resultado de efeito expressivo" (Colette 2010:14).

Cientes da existência de algumas críticas que se faz a utilização de metodologia participativa considerou-se necessário realizar um breve resgate sobre a trajetória de uso e legitimação de métodos e técnicas de pesquisa em Ciências Sociais. Afinal o que se busca na escolha do método e na aplicação de seus instrumentos é possivelmente a denominada verdade científica, que legitima os modelos e as territorialidades de sujeitos e objetos na pesquisa. O debate crítico sobre verdade científica é muito bem explicitado por Foucault quando afirma que: "pode sempre acontecer que se diga o verdadeiro no espaço de uma exterioridade selvagem; mas não se está no verdadeiro sem que se obedeça às regras de uma 'polícia' discursiva que temos de reativar em cada um dos seus discursos" (Foucault 1987:10).

Neste contexto, o processo de definição do método a ser aplicado nesta pesquisa considerou algumas questões cruciais: $\mathrm{O}$ que contribui para a gênese, legitimação e reprodução do discurso científico? O que garante a validação dos dados obtidos em métodos qualitativos e quantitativos? Neste debate, ainda estão muito presentes questões que envolvem uma suposta parcialidade do/a pesquisador/a em relação ao objeto em estudo e também a pertinência ou não das formas de coleta de dados que diminui esta distância entre sujeitos - os que pesquisam e os que estão sendo pesquisados.

Ao longo das últimas décadas do século XX, autores como Foucault (2005) e Morin (2002) realizaram grandes contribuições relacionadas à elaboração metodológica ao questionarem as estruturas cristalizadas no fazer e no dizer científico. Consistem em teóricos que valorizam a proposição de que "cada caso é um caso", proposição que elimina a possibilidade de um modelo fechado, extremamente delimitado e com aplicabilidade universal.

Nesta perspectiva, que relaciona saber e poder na escolha e legitimação metodológica, concordamos com Raquel Stela de Sá (2011) que debate a partir de Foucault questões relacionadas à produção do conhecimento:

$$
\begin{aligned}
& \text { "Arqueologia como uma espécie } \\
& \text { de atividade histórico-política que } \\
& \text { procura responder como os sa- } \\
& \text { beres aparecem e se transformam. } \\
& \text { É a luta, o combate, o resultado do } \\
& \text { combate e, consequentemente, o } \\
& \text { risco e o acaso que vão dar lugar } \\
& \text { ao conhecimento. É somente nes- } \\
& \text { sas relações de luta e poder que } \\
& \text { compreenderemos em que consiste } \\
& \text { para ele o conhecimento. Um con- } \\
& \text { hecimento que é uma ordem do } \\
& \text { resultado, do acontecimento, do } \\
& \text { efeito que pode ser colocado sob o } \\
& \text { signo do conhecer. Ele explica que } \\
& \text { por trás de todo o saber, de todo } \\
& \text { conhecimento, o que está em jogo } \\
& \text { é uma luta de poder." (Sá } 2011: 02 \text { ) }
\end{aligned}
$$

Nesta pesquisa fundamentada em in- 
strumentos de metodologia participativa, se priorizou a atuação efetiva das pescadoras num processo de troca de saberes e seus conhecimentos e experiências que foram valorizados num processo que envolveu discussão, identificação e busca de soluções para problemas que emergem de suas vivências cotidianas na pesca artesanal. Foi considerada a importância de um roteiro, previamente construído, para estimular o diálogo e com a intencionalidade de fomentar a criatividade e a colaboração dos atores sociais envolvidos. ${ }^{2} \mathrm{O}$ processo também contou com a figura do/a moderador/a com a finalidade organizar e orientar a discussão do grupo de trabalho (Colette 2010:14).

O processo de elaboração do instrumental para coleta de dados, nesta pesquisa, foi desenvolvido em diversas fases, nas quais foram elaboradas técnicas de dinâmica de grupo, jogos dramáticos e outras atividades, que objetivaram, por meio de fantasias, diagnosticar situações reais.

A primeira fase consistiu em diálogo e em trocas de saberes entre a equipe que iniciou o projeto. Ao final deste processo foram escolhidas as referên$\operatorname{cias}^{3}$ que deram suporte à trajetória metodológica.

A segunda fase de elaboração da metodologia a ser aplicada nas oficinas itinerantes consistiu numa reunião em Brasília durante os dias 6, 7 e 8 de maio de 2010, com docentes das Universidades Federais de Pernambuco, Bahia, Santa Catarina e Pará, membros do Ministério da Pesca e Aquicultura e
Ministério do Desenvolvimento Agrário e Secretaria de Política para Mulheres. ${ }^{4}$ $\mathrm{Na}$ ocasião, o grupo foi dividido em subgrupos para realizar as tarefas, as quais consistiram em pensar questões e encaminhamentos metodológicos relacionados às atividades das mulheres na pesca, saúde e alimentação. $\mathrm{O}$ resultado gerou as proposições metodológicas que foram aprofundadas e socializadas entre o grupo, por meio virtual, durante um mês após a realização do evento.

Posteriormente, em julho de 2010, foi aplicada em Pernambuco a oficina para realização do diagnóstico elaborado pelo grupo de pesquisa. Este evento ocorreu em um hotel, durante três dias e contou com a presença de 16 pescadoras.

$\mathrm{Na}$ elaboração e realização das oficinas, foram considerados três aspectos centrais que deram sustentação ao processo dialogado: o tema, o grupo e a comunicação.

1) Sobre a definição do tema nas duas experiências acima referenciadas, se organizou o roteiro e se socializou com o grupo de trabalho, buscando-se meios que tornassem atrativa e acessível às pescadoras a discussão das questões que subsidiaram o diagnóstico sobre gênero e trabalho de mulheres na pesca artesanal em cinco estados do Brasil. Entre eles se destacam: Exibição dos filmes: "Acorda Raimundo5", "Dra Marta" e "Vida Maria"; Oficina das Mãos: O que essa mão fez?; Oficina Construção de Rotina Diária; Oficina Diagnóstico da Pesca; Oficina de Identificação - Construção das Bonecas; ${ }^{7}$ Dramatização; Oficinas: Saúde Ocupacional; Oficina: Diagnóstico da Alimentação 
(o processo de cozinhar) (hábito alimentar); Questionário Recordatário da Alimentação; Retrospectiva do que foi realizado; Oficinas: Árvore dos desejos; Apresentação slides do evento e filmagem da dramatização; dinâmicas de grupo.

2) Quanto ao grupo, importante ressaltar que a literatura destaca a necessidade de "planejamento à condução das atividades: a composição do grupo, a dinâmica das relações entre seus integrantes, o nível de "governabilidade" para tomar decisões relativas aos temas trabalhados" (Colette 2010:15). No processo de desenvolvimento da pesquisa com metodologia participativa, considerou-se nos cinco estados brasileiros a existência de grupos anteriormente construídos, articulados por lideranças locais; houve a tentativa de nivelamento das expectativas das participantes, da construção do clima de confiança entre elas e principalmente a realização de dinâmicas para mediação de conflitos. Ainda vale ressaltar que em Pernambuco, o trabalho de preparação para a oficina itinerante no sertão de estado foi iniciado nos dias 10 e 11 de dezembro de 2010, quando foi realizado um encontro, de dois dias, com o grupo de articuladoras e a equipe de pesquisa, para preparar e detalhar o roteiro e atividades a serem desenvolvidas. Nesta ocasião ficou decidido quais as Colônias de Pescadores/as a serem visitadas: Ibimirim, Itacuruba, Jatobá, Santa Maria da Boa Vista e Pedrinhas.

3) No que refere à comunicação, uma das estratégias foi realizar a pesquisa com grupos anteriormente organiza- dos, utilizar meios que tornassem atrativo e acessível a discussão das questões, fomentar no/a moderador/a e no grupo o "saber ouvir até o fim, fazer colocações claras e objetivas e em linguagem acessível, acertar se está sendo compreendido" (Colette 2010:16)

\section{GÊNERO E TRABALHO NA PESCA ARTESANAL}

Importante ressaltar que o tempo é utilizado diferentemente por mulheres e homens. Cavalcanti, Paulo e Hany (2010) no artigo "A pesquisa piloto de uso do tempo do IBGE 2009/2010", apresentado no Fazendo Gênero 9, afirmam que:

"A forma como as pessoas organizam e distribuem seu tempo afeta o bemestar econômico e social e tem impactos sobre sua família e a comunidade onde vivem. No cenário internacional da produção de estatísticas sociais e econômicas, tem se tornado consensual a ideia de que medidas de uso do tempo devem ser incluídas na formulação de indicadores para avaliar as condições de vida da população. (...) como o recurso "tempo" é usado diferentemente entre homens e mulheres, entre os grupos etários, entre pessoas de grupos raciais distintos ou das várias classes sociais. Este tipo de pesquisa capta informações sobre as diferentes atividades que os indivíduos realizam ao longo de um determinado período, em geral 24 horas. Com isso, forma-se um retrato do cotidiano das pessoas, abrangendo todo o leque das atividades humanas."

As autoras destacam ainda que, no que se refere à questão de gênero, as pes- 
quisas de uso do tempo são particularmente importantes, pois as atividades a que homens e mulheres se dedicam refletem os papéis sociais e as desigualdades de condições e oportunidades entre os sexos. Dados obtidos nesta pesquisa sistematizaram as seguintes informações sobre o uso do tempo para as pescadoras:

- Manhã - despertar em média no horário entre $3 \mathrm{~h}$ e $6 \mathrm{~h}$ da manhã; agradecer a Deus; acordar as crianças; fazer o café; caminhar; cuidar da sogra; levar as crianças para a escola/creche; fazer o almoço ou comer na casa da mãe; descascar e vender mariscos; lavar roupa; limpar a casa e buscar as crianças na escola. Almoço às $12 \mathrm{~h}$.

- Tarde - lavar louças; ensinar tarefas dos/as filhos/as; preparar jantar; geralmente não descansam à tarde. As $18 \mathrm{~h}$ servem o jantar.

- Noite - lavar louças; assistir novelas; estudar.

Importante resaltar que uma característica específica do trabalho da pesca no litoral é dependência ao horário da maré. Quando o horário da maré, bom para pescar, é pela manhã, suas atividades domésticas são antecipadas para a noite anterior.

Estes dados evidenciam a denominada "divisão sexual do trabalho"; as atividades domésticas são realizadas pelas mulheres.

Linduína (Ceará) relata que “eu me levan- to de manhã, me levanto cedo, quatro e meia, quatro e quarenta, organizo minhas coisas, eu deixo o meu feijão ou o meu arroz feito, e vou pra maré".

Ainda se apresentaram diferenças na rotina entre as mulheres que convivem com um companheiro e as que estão sozinhas. Algumas pescadoras realizam as atividades de:

- Cuidar do barco;

- Processar o pescado - descascar camarão e marisco, filetar e limpar e o peixe e os vários beneficiamentos de produtos da pesca;

- Confecção ou reparo de rede;

- Colaborar no cultivo dos mariscos;

- Outras atividades.

As pescadoras mais jovens, com filhos pequenos, declararam ter dificuldade em estudar porque faltam creches e assim, muitas vezes, não têm com quem deixar as crianças.

Todas as pescadoras afirmaram que, apesar de despertar tão cedo, não descansam durante a tarde. As atividades realizadas diretamente no mangue ou no mar são definidas pelas tábuas das marés, por isso a rotina na atividade laboral é sempre variável.

Ao sistematizarmos estes dados, torna-se evidente que, apesar do crescimento da atividade feminina no mercado de trabalho, evidenciado pelas crescentes taxas de atividade e de participação feminina na população economicamente ativa, na pesca artesanal permanece, o que Lombardi (2010:40) denomina de padrão da divisão sexual 
do trabalho doméstico, segundo a qual a mulher é a principal responsável pelo cuidado com os filhos, a casa e a família.

Segundo (Sorj 2010:57) estas “desigualdades e diferenças de gênero repousam sobre uma norma social que associa o feminino à domesticidade e que se expressa na divisão sexual do trabalho, atribuindo prioritariamente às mulheres a responsabilidade com os cuidados da família". Essa naturalização reduz a atividade das pescadoras à categoria de "ajudantes", mesmo que muitas vezes sejam elas as provedoras das despesas domésticas.

A autora, ao definir cuidado, possibilita compreender melhor a naturalização da mulher como coadjuvante na cadeia produtiva da pesca. Para Sorj (2010: 58), cuidado é um termo usado para referir-se:

"A um conjunto de atividades diversificadas envolvidas no cuidado dos outros e pode assumir a forma de trabalho não pago, dedicado aos membros da família, ou de trabalho pago feito para outros. Concretamente, essas atividades incluem cuidar das crianças, idosos, doentes, deficientes, bem como realizar tarefas domésticas como limpar, arrumar, lavar, passar, cozinhar etc."

Esta invisibilidade da mulher no plano profissional na pesca artesanal contribui também para um certo protagonismo masculino no interior dos movimentos sociais da categoria. Sobre esta outra forma de marginalização das pescadoras, ou seja, a dificuldade de participação das mulheres nos movimentos sociais da pesca artesanal,
(Maneschy, Alencar e Nascimento 1995: 82) afirmam que "rever, questionar e criticar o padrão de relações de gênero e o papel secundário das atribuições femininas é, portanto, tocar em visões de mundo e em atitudes muito arraigadas". As autoras questionam a invisibilidade da pescadora na cadeia produtiva da pesca, considerando que elas geralmente aprenderam a arte de pescar com suas mães e geralmente são elas quem transmitem o conhecimento e a familiaridade com a atividade pesqueira às novas gerações, na medida em que necessitam levá-los muitas vezes às suas atividades laborais, na ausência de creches nestas comunidades (op. cit.:86).

\section{DIAGNÓSTICO DA PESCA}

As pescadoras apontam a coleta do marisco como sua principal atividade; em algumas localidades elas pescam, coletam e/ou cultivam.

As espécies de peixes indicadas nos cinco estados são: Manjuba, Saúna, Tainha, Sardinha, Carapicú, Carapeba, Raia, Bagre, Camurim, Mororó, Sôia, Moréia, Aniquim, Tamatá, Traira, Pescada Branca, Acaratingo, Jacundá, Pratiqueira no curral, Aracu, Gabri, Gó, Banderado, Salema, Boca Mole, Manjubão. Bitreque, Salminha.

As espécies de mariscos referenciadas nos cinco estados são: Sururu, Ostra, Caranqueijo, Turú, Siri duro e mole, Taioba, Unha de Veio, Redondo, Camarão, Maraquani, Marisco Pedra, Búzios. 
No Ceará elas também coletam e cultivam algas. Em Santa Catarina, no Ceará e no Pará realizam cultivo de ostras.

Marileide (Ceará) afirma que "eu trabalho lá na colônia junto com a presidente e cultivo ostras, lá com outras mulheres do pontal como a maior parte do Fortim, a gente está no pontal e cada uma tem um grupo, e nós formamos seis grupos no cultivo de ostra, cada grupo tem sua mesa".

No que se refere à comercialização, indicaram formas diversificadas, como por exemplo:

- Nas praias nos finais de semana aos banhistas.

-Diretamente ao consumidor final;

- Ao atravessador;

- Beneficiado (cozido, temperado);

- Troca por outros produtos lenha, sal, bolo;

- Consumem em suas casas e;

- Dependendo da quantidade, divide com as crianças que as ajudam na pesca.

Uma pescadora de Santa Catarina afirmou que "chegou do mar é com a gente", o que demonstra que as atividades desenvolvidas pelas mulheres na cadeia produtiva da pesca não podem ser resumidas a coletar e pescar.

No que se refere ao aspecto econômico, a informação geral é de que a renda é baixa, sendo difícil conseguir o equivalente a um salário mínimo mensal nas regiões Norte e Nordeste. Poucas são as que recebem um salário fixo, com exceção das que trabalham em cooperativa, são aposentadas ou pensionistas. A pesca é descrita como uma atividade sazonal, com forte variação entre verão e inverno, tanto na coleta como na comercialização. Os problemas ambientais advindos da urbanização e da industrialização geralmente diminuem a quantidade e qualidade do pescado.

Quanto ao acesso às áreas da pesca existem relatos de perigos, às vezes é necessário fazer acordo com fazendeiros para poder pescar; muitas vezes a dificuldade é a distância para chegar ao mar e algumas afirmaram ser necessário levar um homem para remar. No Pará houve vários relatos de mulheres que citaram a pirataria no mar como a principal dificuldade encontrada por pescadoras e pescadores.

Ao serem indagadas sobre as dificuldades por elas vivenciadas na sua atividade de trabalho, relataram principalmente que:

- Muitas não possuem canoa, também faltam recursos para a manutenção das redes, embarcações, barcos e falta de isca para pesca;

- Afirmam que pescar todo o tempo dentro d'água em contato com água viva, bactérias, peixes e outros objetos cortantes é muito perigoso. Algumas sofrerem acidentes com peixes (por exemplo aniquim), ostras e tocos da madeira no mangue;

- No inverno a renda cai por causa da escassez do produto e também dos consumidores; 
- A condição subalterna das mulheres, na maioria das Colônias de Pescadores/as e seu baixo poder de atuação nas decisões;

- A violência por dividir o espaço da pescaria com usuários de drogas.

Os dados acima mencionados demonstram o caráter precário da atividade da pesca artesanal para as mulheres, ainda mais se considerarmos que a atividade laboral é fragmentada entre outras tantas atividades. Sobre este tema, Sorj (2010:5) destaca que:

"O quadro que emerge hoje está longe de realizar um modelo equitativo de distribuição do trabalho social entre os sexos. Os homens continuam a investir o seu tempo prioritariamente no trabalho remunerado e um crescente número de mulheres são levadas a acumular trabalho remunerado e trabalho não remunerado."

A autora ainda desenvolve a temática de políticas públicas a partir do enfoque de gênero, que pode subsidiar pesquisas que tratam desta abordagem (Sorj 2010: 59-65).

Neste trabalho precário, perguntamos quais as outras fontes de renda destas mulheres: muitas recebem benefícios do Programa Bolsa Família, que variam entre $\mathrm{R} \$ 68,00, \quad \mathrm{R} \$ 80,00, \quad \mathrm{R} \$ 96,00$, $\mathrm{R} \$ 112,00$ e $\mathrm{R} \$ 127,00$; algumas trabalham nas frentes de serviços oferecidos pelas prefeituras durante alguns meses do ano e/ou realizam atividades mal remuneradas nas casas dos veranistas, durante o verão.

No que se refere aos direitos sociais,
Linduína (Ceará) chama atenção sobre a importância dos movimentos sociais, no processo de reivindicações, ao relatar que: “ eu pesco desde..., eu posso dizer que desde que nasci, porque minha mãe era marisqueira pescadora também, e o tempo foi avançando e foi modernizando, porque no tempo de minha mãe nem carteira de pescador ela nunca teve, e graças a Deus hoje com a evolução, com nosso trabalho, comunitário, a gente foi se juntando porque a gente tem que fazer parceria e trabalhar com outras pessoas pra ficar conhecendo os nossos direitos e deveres."

\section{CONSIDERAÇÕES FINAIS}

Os relatos das mulheres explicitam sua dependência às atividades domésticas e de cuidado, por exemplo:

- As tarefas domésticas são realizadas, na maioria das vezes, pelas mulheres. Algumas comentaram que o marido ajuda, mas sempre necessita ser solicitado, incentivado. $\mathrm{Na}$ maioria das vezes, elas acordam antes de todos e os chamam para o café.

- Assim, além do trabalho profissional de pescar, elas ainda realizam a maioria das tarefas: levar filho ao médico, cuidar da casa, suprir as atividades de lazer (quando existe), fazer as atividades domésticas e ajustar receitas e despesas no orçamento doméstico.

- Muitas apontam que o mari- 
do não colabora nas atividades domésticas, mas acordam cedo para trabalhar. Outras informam que alguns homens gostam de cozinhar, e se precisar, se solicitado, colaboram.

- Uma questão que apareceu em quase todas as falas refere-se à dupla jornada de trabalho, já que trabalham nas atividades da pesca e são responsáveis pelas tarefas domésticas, mesmo quando convivem com alguém (marido, filhos, netos) que colaboram.

- Esta situação mostra a dificuldade das mulheres, principalmente com filhos pequenos, de participarem de associações, cooperativas, movimentos soci- ais e até mesmo de lutarem por espaço nas Colônias de Pescadores/as, porque, além de irem ao mar, rio ou mangue, elas ainda debulham, cozinham e descascam o marisco durante toda a semana. Mesmo assim, várias pescadoras atuam em trabalhos comunitários na igreja, nos clubes de mães, nas associações de moradores etc.

- Afirmam que o trabalho próximo de suas casas, no rio, mangue, processando o pescado, permite realizar as tarefas domésticas e acompanhar os filhos, situação existente mesmo quando os companheiros são pescadores e/ou maricultores.

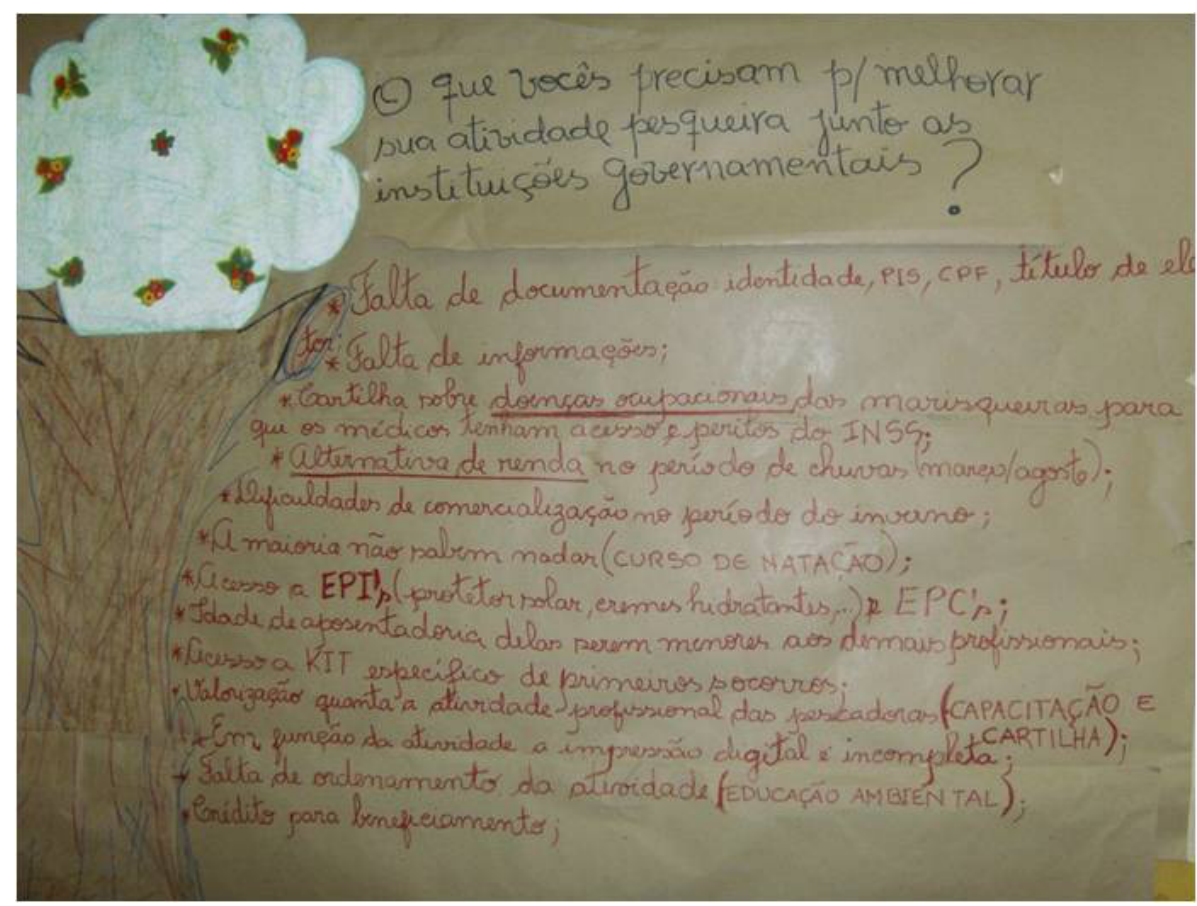

Figura 1 - “Árvore dos Desejos.” Fotografia de Maria do Rosário de Fátima Andrade Leitão 
- Quanto aos filhos e filhas, netos e netas, algumas delas possuem filhos/as que também são pescadores/as e maricultores/ as, mas também apontaram diversas outras profissões.

- Muitas afirmam que esperam que seus filhos/as, netos/as não trabalhem na pesca. Para elas a pesca é muito triste e a vida de pescador/a é sofrida; a pesca "está ruim", sendo "humilhante" para o pescador/a receber salários cada vez mais baixos.

- Existe o sonho da atividade de carteira assinada, visualizada geralmente em outras profissões.

A dinâmica "A árvore dos desejos" (Figura 1) indica conjuntamente com algumas falas, exemplos e situações por elas vivenciadas, as principais questões relacionadas ao trabalho das mulheres na pesca artesanal.

\section{NOTAS}

${ }^{1}$ Nó difícil de desatar.

${ }^{2}$ Foram realizadas reuniões anteriores à realização do evento nos dias 16/06, 22/06, 30/06, 07/07, 14/07, 22/06 e 29/07 de 2010 com o objetivo de construir em conjunto detalhamentos das atividades desta oficina, inclusive a construção dos painéis a serem preenchidos. As reuniões contaram com a presença de Maria do Rosário de Fátima Andrade Leitão na coordenação e Maria José Pereira Diniz, Maria Solange da Silva, Iêda Litwak de Andrade Cézar, Claudia França Valença Lopes, Claudia Maria de Lima e Júlia Xavier Souto, algumas vezes Marcos Miliano e Ivan Leitão, o que permitiu maior entrosamento da equipe e também agilidade na realização das atividades propostas.

${ }^{3}$ A) Facilitando oficinas da teoria à prática. Disponível em: http://www.iteco.be/var/ www/iteco/www.iteco.be/IMG/pdf/Facilitando_oficinas.pdf. Acesso em: 05/04/2010.

B) Aguilar, Lorena. Sobre marinos, marinas, mares y mareas:perspectiva de género en zonas marino-costeras/Lorena Aguilar, Itzá Castañeda. $1^{a}$ ed. San José, C.R.:UICN: Absoluto, 2000.

C) Manual de metodologias participativas para o desenvolvimento comunitário. Disponível em: http://www.ecoar. org.br/website/download/publicacoes/ manual_de_metodologias_participativas_ para_o_desenvolvimento_comunitario_ VERS\%C3\%83OFINAL.pdf. Acesso em: 05/04/ 2010.

${ }^{4}$ Participaram da reunião: Maria do Rosário de Fátima Andrade Leitão (UFRPE); Mara Coelho de Souza Lago e Carmen Silvia Rial (UFSC); Luzia Miranda Álvares e Maria Cristina Alves Maneschy (UFPA); Paulo Gilvane Lopes Pena e Thaís Mara Dias Gomes (UFBA); Ana Luiza Spinelli Pinto (MPA); Tereza Candida Diniz Gonçalves e Vivianny Mary Juca Bezerra (Ong Flor da Terra - CE), entre outros.

${ }^{5}$ Quais as questões apresentadas no filme que refletem nosso dia a dia: nas relações de trabalho; na divisão sexual do trabalho; na economia familiar; na participação feminina.

${ }^{6}$ Objetivo: resgatar a história de vida dos (as) participantes, contribuindo para sua autoestima e autoconhecimento de sua condição de trabalho. Pedir para que cada participante faça na folha A4 um molde de uma de suas mãos e em seguida solicitar que os (as) participantes escrevam: $\mathrm{O}$ que essa mão já fez? Reflexão: cada participante contar a sua experiência. 
${ }^{7}$ Construção de Boneco (a): Trabalho em Pequenos grupos (10 grupos de 3 pessoas)

Cabeça: Identidade (Quem sou eu / Onde Moro? / O que faço? Onde?/ Qual minha idade?)

Mãos: Trabalho - (Quanto tempo trabalho na pesca?/ Meu marido é pescador? / Ajuda no meu trabalho como pescadora? Ajuda em casa? Em que? / Quantos filhos têm? Ajudam no meu trabalho?)

Coração: Sentimentos (Alegrias e Tristezas de realizar esse trabalho? Condições que limitam o seu trabalho na pesca? (menstruação, gravidez).

Pés - Nossos caminhos: (O que enfrentamos todos os dias?). Tempo: $01 \mathrm{~h} 30 \mathrm{~min}$.

${ }^{8}$ Dinâmica: Teatro - Acesso às Políticas Públicas. Trabalho em Grupo: Dividir o grupo em 04 - 05 subgrupos. Instituições/ Entidades: INSS, Colônias de Pescadores, Ministério da Pesca e Aquicultura. Solicitar que cada grupo escolha uma instituição ou entidade para representar a forma de atendimento e como tem sido garantido o acesso das mulheres as políticas públicas. Cada grupo deverá representar o atendimento, colocando a forma de atendimento, garantia de acesso, principais benefícios solicitados. Os(as) participantes dos outros grupos deverão destacar em tarjetas os principais pontos destacados pelo grupo que fez a representação e complementar, se necessário as informações.

\section{REFERÊNCIAS}

Cavalcanti, L. G. de A., M. A. Paulo \& F. E. S. Hany. 2010. A pesquisa piloto de uso do tempo do IBGE 2009/2010, in Fazendo Gênero 9, Florianópolis: UFSC. Disponível em http:// www.fazendogenero.ufsc.br/9/resources/ anais/1278295122_ARQUIVO_artigoIBGE-APesquisaPilotodeUsodoTempodoIB-
GE2009-2010.pdf. Acesso em 05/01/2012.

Colette, M. M. 2010. Moderação, in Metodologia Participativa: uma introdução a 29 instrumentos. Organizado por M. Brose. Porto Alegre: Tomo Editorial.

Foucault, M. 2005. A ordem do discurso. São Paulo: Loyola.

Lombardi, R. M. 2010. A persistência das desigualdades de gênero no mercado de trabalho, in Divisão sexual do trabalho, estado e crise do Capitalismo. Organizado por A. Costa, M. B. Ávila, V. Soares e V. Ferreira, pp. 33-56. Recife: SOS Corpo - Instituto Feminista para a Democracia.

Maneschy, M. C., E. Alencar e I. H. Nascimento. 1995. Pescadoras em busca de cidadania, in $A$ mulher existe? Uma contribuição ao estudo da mulher e gênero na Amazônia. Organizado por M. L. M. Álvares e M. A. D’Incao, pp. 81-96. Belém: GEPEM.

Morin, E. 2002. OMétodo 4. Porto Alegre: Sulina.

Sá, R. S. de. A arqueologia: como os saberes aparecem e se transformam. Disponível em: http://vsites.unb.br/fe/tef/filoesco/foucault/art11.pdf. Acesso em: 02/05/ 2011.

Sorj, B. 2010. Os cuidados coma família e as desigualdades de gênero e de classe, in Divisão sexual do trabalho, estado e crise do Capitalismo. Organizado por A. Costa, M. B. Ávila, V. Soares e V. Ferreira, pp. 57-65. Recife: SOS Corpo - Instituto Feminista para a Democracia.

Recebido em 05/03/2012.

Aprovada em 15/11/2012. 


\section{ANEXO 1}

Equipe que colaborou na realização do Projeto nos cinco estados.

Coordenação: Maria do Rosário de Fátima Andrade Leitão e Maria Luiza Spinelli

Núcleos de Pesquisa envolvidos

\section{DESENVOLVIMENTO E SOCIEDADE}

Dra. Maria do Rosário de Fátima Andrade Leitão - UFRPE

Mestranda Claudia Maria de Lima POSMEX-UFRPE

Ivan Pereira Leitão - Professor Universidade de Pernambuco

Dimas Brasileiro - Professor Instituto federal - Mestre em História

Júlia Xavier Souto - Graduanda em Economia Doméstica - UFRPE)

Juliana Andrade Leitão - Mestre -POS-

MEX - UFRPE - Fotógrafa/Jornalista

Marcos Miliano - Sociólogo

Maria Solange da Silva - Socióloga

Rejane Maria de Lima - Técnica

Clodoaldo de Souza Cavalcante Neto - Sociólogo

Fernando Antônio Duarte Barros Júnior - Mestre em Antropologia

Francisco Assis de Andrade Costa Engenheiro Agrônomo

Pedro Henrique Dias Inácio - Mestre em História

Phelippo de Oliveira Cordeiro Vanderlei - Biólogo
2. NAVI/GAUM - NÚCLEO DE ANTROPOLOGIA AUDIOVISUAL E ESTUDOS DA IMAGEM/GRUPO DE ANTROPOLOGIA URBANA E MARÍTIMA:

Dra. Carmen Silvia de Moraes Rial - UFSC

Dra. Mara Coelho de Souza Lago - Núcleo de Pesquisas Margens: Modos de Vida, Famillia e Relações de Gênero - UFSC

Dra. Angela Maria de Souza - Antropóloga

Dranda. Maria Elisabeth Goidanich PPGICH - UFSC

Dranda. Viviane Kraieski de Assunção - PPGAS - UFSC

Valentine Godolphim - Graduanda de Ciências Sociais - Bolsista de Iniciação Científica/CNPQ - NAVI

Ana Paula Santos - Graduanda de Ciências Sociais - Bolsista de Iniciação Científica/CNPQ - NAVI

Mestrando Maycon Mello-PPGAS-UFSC

Mestranda Jimena Massa-PPGAS_UFSC

Denise Gomes Silva Moraes Cavalcante - Graduanda de Cinema

\section{GEPEM - GRUPO DE ESTUDOS E} PESQUISAS "ENEIDA DE MORAES"/UFPA

Dra. Maria Luzia Miranda Alvares - UFPA

Dra. Maria Cristina Maneschy - UFPA

- Carla Moreira-bolsista GEPEM/PROAD

- Murilo Cristo Figueira - bolsista/PIPES

- Thiago Paiva - bolsista/PIPES

- Keyla Araújo - bolsista/PIPES 
CONSELHO PASTORAS DOS PESCADORES - PARÁ

Sueli Miranda

Marlucia Mascarenhas Valério

UNIVERSIDADE FEDERAL DA BAHIA

Dr. Paulo Gilvane Lopes Pena - UFBA

Thaís Mara Dias Gomes - Mestranda UFBA
ONG FLOR DA TERRA - CEARÁ

Tereza Candida Diniz Gonçalves

Vivianny Mary Juca Bezerra

SECRETARIA DE POLÍTICAS PARA MULHERES -PARTICIPARAM DE REUNIÕES

Márcia Leporace

Daniela Alarcom

Luciana Mandelli

\begin{tabular}{lllll}
\multicolumn{5}{c}{ PESCADORAS } \\
PERNAMBUCO & PARÁ & PARAÍBA & SANTA CATARINA & CEARÁ \\
Joana & Mariléia & Marinalva & Nair & Adriana \\
Mousinho & & & & \\
Vilma & Elieti & Sidicleide & Nilza & Iracema \\
Lenilda & Anácia & Josineide & Nara & Cosminha \\
Ana Lúcia & Dilvane & Luzia & Iva & Tobias \\
Ladjane & Sandra & Socorro & Áurea & Ana \\
Francelina & Manuelita & Gilvanir & Geovana & Fátima \\
Lindalva & Ana Lúcia & & Valdenice & Tamiris \\
Edileusa & Angélica & & Vera & Irelda \\
Natércia & Marialinelda & & Zezá & Elineuda \\
Ana Paula & Fernada & & Rose & Sinônia \\
Valdirene & Ivanete & & Nelza & Erineide \\
Viviane & Analia & & Rafaela & Martilene \\
Claudenice & & Lúcia & Débora (Aracati) \\
Laudeni & & & Alzira & Raimunda (Fortim) \\
Lenilsa & & & Francisca & Neuma (Fortim) \\
Maria José & & & & Lourdes (Fortim) \\
Rosete & & & & Eneida (Fortim) \\
& & & & Marileide (Fortim) \\
& & & & Rivanda (Fortim)
\end{tabular}

